\title{
Moderating role of the MAOA genotype in antisocial behaviour
}

\author{
David M. Fergusson, Joseph M. Boden, L. John Horwood, Allison Miller and Martin A. Kennedy
}

\section{Background}

Recent studies have examined gene $\times$ environment $(\mathrm{G} \times \mathrm{E})$ interactions involving the monoamine oxidase A (MAOA) gene in moderating the associations between exposure to adversity and antisocial behaviour. The present study examined a novel method for assessing interactions between a single gene and multiple risk factors related to environmental and personal adversity.

\section{Aims}

To test the hypothesis that the presence of the low-activity $M A O A$ genotype was associated with an increased response to a series of risk factors.

\section{Method}

Participants were 399 males from the Christchurch Health and Development Study who had complete data on: (a) MAOA promoter region variable number tandem repeat genotype; (b) antisocial behaviour (criminal offending) to age 30 and convictions to age 21; and (c) maternal smoking during pregnancy, IQ, childhood maltreatment and school failure.

\section{Results}

Poisson regression models were fitted to three antisocial behaviour outcomes (property/violent offending ages 15-30; and convictions ages 17-21), using measures of exposure to adverse childhood circumstances. The analyses revealed consistent evidence of GXE interactions, such that those with the low-activity MAOA variant who were exposed to adversity in childhood were significantly more likely to report offending in late adolescence and early adulthood.

\section{Conclusions}

The present findings add to the evidence suggesting that there is a stable GXE interaction involving MAOA, a range of adverse environmental and personal factors, and antisocial behaviour across the life course. These analyses also demonstrate the utility of using multiple environmental/ personal exposures to test $\mathrm{G} \times \mathrm{E}$ interactions.

\section{Declaration of interest}

None.
In 2002 Caspi and colleagues published a paper examining the role of the monamine oxidase A gene (MAOA) in the development of antisocial behaviours. ${ }^{1}$ Using data from the Dunedin Multidisciplinary Health and Development Study (DMHDS), Caspi et al were able to show consistent gene $\times$ environment $(\mathrm{G} \times \mathrm{E})$ interactions between $M A O A$ and exposure to childhood maltreatment in the development of antisocial behaviour patterns. In this interaction, carriers of the low-activity variant of $M A O A$ showed greater increases in rates of antisocial behaviour following exposure to childhood maltreatment than did the corresponding group of those with the high-activity variant.

Since this paper there have been a number of studies which have confirmed the existence of a $\mathrm{G} \times \mathrm{E}$ interaction involving $M A O A$ and childhood maltreatment in the development of antisocial behaviours. ${ }^{2-13}$ For example, Beach et al, ${ }^{2}$ using a sample of 538 males and females, found evidence of an interaction between MAOA genotype and childhood maltreatment in the prediction of both antisocial personality disorder and major depression. Also, Weder et al, ${ }^{3}$ using a case-control design with 114 children, reported a significant $M A O A \times$ maltreatment interaction in predicting aggression. On the other hand, not all studies have observed an $M A O A \times$ maltreatment interaction. ${ }^{14-18}$ For example, Huizinga et al, ${ }^{14}$ in a study of 277 males from the US National Youth Survey Family Study, did not find evidence of a significant $M A O A \times$ maltreatment interaction in the prediction of six outcomes related to antisocial behaviour. Also, Prichard et $a l^{16}$ did not find an interaction between MAOA and childhood adversity exposure in predicting externalising problems and antisocial behaviour in a large sample $(n=1002)$. These inconsistencies suggest the need for further replications of the $G \times E$ interaction involving $M A O A$ and childhood maltreatment.
In addition, recently published evidence suggests that $\mathrm{G} \times \mathrm{E}$ interactions involving $M A O A$ in the development of antisocial behaviours may not be confined to childhood maltreatment. Specifically, Wakschlag and colleagues ${ }^{19}$ reported a significant $\mathrm{G} \times \mathrm{E}$ interaction involving $M A O A$ and maternal smoking during pregnancy. In line with the findings for childhood maltreatment, this study found that male carriers of the low-activity variant of $M A O A$ tended to show greater increases in conduct disorder symptoms following exposure to smoking during pregnancy than did the corresponding high-activity MAOA group. The findings that $M A O A$ may interact with at least two environmental factors (maltreatment, maternal smoking) in the development of antisocial behaviours suggests the possibility of more general $\mathrm{G} \times \mathrm{E}$ interactions in which $M A O A$ activity genotype interacts with multiple risk factors for antisocial behaviour, with the findings for childhood maltreatment and maternal smoking being special cases of this more general relationship. It may be conjectured that the use of multiple environmental exposures as tests of $\mathrm{G} \times \mathrm{E}$ interactions may provide more robust findings than have proved to be the case previously.

In this paper, we explore this conjecture by reporting on an analysis of the interactions between $M A O A$ and multiple risk factors in the development of antisocial/criminal behaviours using data gathered over the course of the Christchurch Health and Development Study (CHDS). The CHDS is a longitudinal study of a birth cohort of 1265 children born in Christchurch, New Zealand, who have been studied from birth to age 30 . The risk factors considered include: maternal smoking during pregnancy; family material deprivation; childhood IQ; childhood maltreatment exposure; and school failure. The aims of the analysis are to: 
1 examine $\mathrm{G} \times \mathrm{E}$ interactions involving each of the risk factors and MAOA genotype;

2 develop multivariate models of $\mathrm{G} \times \mathrm{E}$ interactions between $M A O A$ and multiple risk factors for antisocial/criminal behaviours, in order to develop a general approach for modelling $\mathrm{G} \times \mathrm{E}$ interactions using multiple measures of environmental exposure.

\section{Method}

\section{Sample}

Data were gathered during the course of the CHDS. In this study a birth cohort of 1265 children born in the Christchurch (New Zealand) urban region in mid-1977 has been studied at birth, 4 months, 1 year and annually to age 16 years, and again at ages 18,21, 25 and 30 years. $^{20,21}$ All phases of the study were subject to ethical approval from the Canterbury (New Zealand) Regional Health and Disability Ethics Committee. The present analysis is based on a sample of 399 male cohort members who were assessed on antisocial behaviour outcomes in late adolescence and early adulthood (ages 15-30 years) and who were successfully genotyped for MAOA. This sample represented $66 \%$ of the surviving cohort of males.

\section{DNA preparation}

Between ages 28 and 30, sample members were asked to provide a peripheral blood sample for DNA analysis: 446 male participants agreed, with most $(91 \%)$ providing a blood sample from which DNA was extracted using a sodium chloride/phenol procedure. For the remaining participants, saliva was collected using Oragene $^{\mathrm{TM}}$ collection kits (DNA Genotek, Ottawa, Canada) and DNA was extracted according to the supplier's instructions.

\section{MAOA genotyping}

Polymerase chain reaction was performed essentially as described by Sabol et $a l^{22}$ and Caspi et al. ${ }^{1}$ Reactions were carried out on an Eppendorf MasterCycler-EP using the primers MAO APT1 (5'-ACAGCCTGACCGTGGAGAAG- $3^{\prime}$ ) and MAO APB1 (5'-GAACGGACGCTCCATTCGGA-3') (Invitrogen). MAO APT1 was $5^{\prime}$-labelled with the FAM fluorophore. Polymerase chain reaction conditions were as follows: initial 2-minute denaturing step at $95^{\circ} \mathrm{C}$, followed by 35 cycles of $94^{\circ} \mathrm{C}$ for $30 \mathrm{~s}, 60^{\circ} \mathrm{C}$ for $30 \mathrm{~s}$ and $72^{\circ} \mathrm{C}$ for $40 \mathrm{~s}$, and a final extension phase of $72^{\circ} \mathrm{C}$ for 5 min. Reactions were performed in $10 \mu \mathrm{l}$ volume using PCR buffer with $1.5 \mathrm{mM} \mathrm{MgCl}_{2}$ (Roche), $\sim 50 \mathrm{ng}$ of genomic DNA, $500 \mathrm{nM}$ of each primer, $200 \mu \mathrm{M}$ each dNTP (Fisher Biotec) and 0.5 units of Taq-TI (Fisher Biotec). Polymerase chain reaction products were assayed on an Applied Biosystems 3130xl genetic analyser, set to fragment analysis mode, using POP7 polymer (Applied Biosystems) and GeneScan 500 LIZ (Applied Biosystems) size standard. Results were analyzed using GeneMapper v4.0 software for Windows (Applied Biosystems). On the basis of this genotyping, 150 males were classified as having the low-activity MAOA genotype (one individual had 2.5, the rest had 3 repeats) and 249 males were classified as having the high-activity MAOA genotype (3.5, 4 or 5 repeats). Allele repeat length grouping was as essentially as described and justified by Caspi et al. ${ }^{1}$ It should be noted that additional analyses in which the nine cohort members with 5 repeats were classified as the low-activity genotype $^{1}$ revealed the same pattern of results as those presented below.

\section{Antisocial (criminal) behaviour outcome measures (ages 15-30)}

The following measures were used to assess antisocial behaviour (criminal offending) outcomes during the period 15-30 years.

\section{Self-reported property offending and self-reported violent offending,} ages $15-30$

At ages 16, 18, 21, 25 and 30, respondents were questioned about their criminal behaviours since the previous assessment using an instrument based on either: (a) the Self-Report Early Delinquency Scale $^{23}$ at age 16, or (b) the Self-Report Delinquency Inventory $(\mathrm{SRDI})^{24}$ at ages 18-30, supplemented by additional customwritten survey items. This information was used to derive count measures of the number of self-reported property and/or violent offences committed in each year from age 15 to age 30. Property offences were defined to include theft, burglary, breaking and entering, vandalism, fire setting, and related offences; violent offences included assault, fighting, use of a weapon, or threats of violence against a person. For the purposes of the present analyses, the number of offences committed in each year was summed over the period 15-30 years to create two overall scores reflecting the total number of property offences and the number of violent offences.

\section{Officially recorded property/violence convictions, ages 17-21}

Data on convictions over the period 17-21 years were obtained from records held by the New Zealand police. These records were obtained following signed and informed consent from the young person. Of the 1011 cohort members asked for permission to search their police records, $97.3 \%$ agreed to provide permission and $2.7 \%$ declined. For each participant, a record of the date of arrest, type of offence, date of court appearance, number of convictions and sentence was gathered. For the purposes of the present analysis, data on convictions were classified to provide a measure of convictions for property or violent offences. Property offences included theft, burglary, breaking and entering, wilful damage, fire setting, and related offences. Violent offences included assault, fighting, robbery, use of a weapon, threats of violence against a person, and similar offences. The numbers of convictions for each type of offence were then summed over the period to create an index of the number of property and violent convictions during the period 17-21 years.

\section{Environmental/personal risk factors for criminal behaviour}

The following measures were used to examine the environmental and personal risk factors for criminal behaviour in late adolescence and early adulthood. These factors were chosen from the study database because: (a) they were known to be predictors of later criminal behaviour, based on earlier studies of the CHDS cohort; ${ }^{25-28}$ and (b) they displayed consistent interactions with the $M A O A$ genotype (see Results). A range of other measures were also considered, but these did not show statistically significant interactions with the MAOA genotype, and were therefore omitted from further consideration.

\section{Maternal smoking during pregnancy}

At the time of the birth of the cohort member, his mother was questioned about her cigarette smoking during each trimester of pregnancy. Cohort members whose mothers reported smoking at least one cigarette per day during any trimester were classified as having been exposed to prenatal cigarette smoking (30.8\% of the sample). 


\section{Family material deprivation (ages 0-10)}

At each year a global assessment of the material living standards of the family was obtained by means of an interviewer rating. Ratings were made on a five-point scale that ranged from 'very good' to 'very poor'. These ratings were averaged over the 10 -year period to give a measure of typical family living standards during this period. For the purposes of the present investigation, this measure was divided into tertiles representing high, medium, and low levels of exposure to family material deprivation during the period $0-10$ years.

\section{Child cognitive ability (IQ)}

Cognitive ability was assessed at ages 8 and 9 using the revised Wechsler Intelligence Scale for Children (WISC-R). ${ }^{29}$ Total IQ scores were computed on the basis of results on four verbal and four performance subscales. The split half reliabilities of these scores were 0.93 at age 8 and 0.95 at age 9. The observed WISC-R total IQ scores at ages 8 and 9 were combined by averaging over the two administrations. For the purposes of the present investigation, these scores were divided into quartiles.

\section{Childhood maltreatment exposure}

Exposure to childhood maltreatment was defined as exposure to either significant childhood sexual abuse or childhood physical abuse, as follows.

Exposure to childhood sexual abuse was assessed on the basis of retrospective reports obtained at ages 18 and 21 years. Participants were questioned about their experience of a range of 15 abusive experiences prior to age 16, and for each incident reported further detail was gathered on the nature and context of the abuse. ${ }^{30,31}$ On the basis of this questioning participants were classified into four groups reflecting the most severe form of abuse reported at either age: no childhood sexual abuse; non-contact childhood sexual abuse (e.g. indecent exposure, lewd or threatening sexual comments); contact childhood sexual abuse involving inappropriate touching of genital areas; and attempted/completed sexual penetration.

Exposure to childhood physical abuse was assessed on the basis of retrospective reports obtained at ages 18 and 21 of the extent to which the participant's parent(s) were reported to have used methods of physical punishment during childhood $(<16$ years).$^{30,32}$ For the purposes of the present analysis participants were classified into three groups reflecting the severity of physical punishment experienced during childhood: parents never or rarely used physical punishment; at least one parent regularly used physical punishment; and at least one parent used frequent, severe or harsh physical punishment.

In order to create a measure of exposure to significant childhood sexual abuse and childhood physical abuse for the purposes of the present investigation, cohort members who were exposed to either (a) any form of sexual abuse (non-contact or contact abuse) or (b) either regular or harsh/severe levels of physical punishment were classified as having been exposed to significant childhood sexual abuse or childhood physical abuse (22.4\% of the sample). Previous studies of the CHDS cohort have found that these classifications were unlikely to have been affected by current mental health state. ${ }^{30,33}$

\section{Leaving school without qualifications}

At age 18, sample members were questioned regarding their educational history. In particular, information was obtained on the number of School Certificate subjects attempted and grades received. The New Zealand School Certificate examinations consisted of a series of national exams taken by the majority of students in their third year of high school (Year 11). Typically, students took between four and six examination subjects, for which they received a grade ranging from A to E. For the purposes of the present analysis, sample members were classified as leaving school without qualifications if they had left school by age 18 without achieving at least one $\mathrm{A}, \mathrm{B}$ or $\mathrm{C}$ grade in School Certificate examinations (19.9\% of the sample).

\section{Statistical analyses}

In order to model the extent to which there were interactions between MAOA activity level genotype and environmental/ personal factors, a series of moderated Poisson regression models with correction for overdispersion were fitted to the data using SAS v.9.01 for Windows. The advantage of using moderated models, nested within MAOA levels, is that these models avoid problems of multicollinearity and inflation of error that arise from testing multiplicative interaction effects within a Poisson regression framework, ${ }^{34}$ while still providing multiple tests of interaction within a single model (see equation 2). These models were of the form:

$$
\log \left(Y_{i}\right)=B_{0}{ }^{k}+B_{j}^{k} X_{i j}+U_{i}
$$

where $\log \left(Y_{i}\right)$ was the logarithm of the number of offences or convictions, $X_{i j}$ was the individual's score for a particular predictor (maternal smoking during pregnancy; family material deprivation; childhood IQ; childhood maltreatment; school achievement); and $U_{i}$ was the model disturbance. In this model the intercept parameters $B_{0}{ }^{k}$ and slope parameters for predictor $B_{j}^{k}$ were permitted to vary by $M A O A$ activity level $k(k=1$ or 2 representing low and high $M A O A$ groups respectively). The parameters $B_{0}{ }^{k}$ thus represent the main effects of MAOA activity level and the parameters $B_{j}^{k}$ represent the effect of the predictor within levels of $M A O A$ (representing the $\mathrm{G} \times \mathrm{E}$ interaction effect). Tests of equality of the slope parameters across MAOA activity levels were based on a $\log$ likelihood ratio $\chi^{2}$-tests of the null hypothesis that $H_{0}: B_{j}{ }^{1}=B_{j}{ }^{2}$, and served as the test of $\mathrm{G} \times \mathrm{E}$ interaction.

In the next step of the analyses, the models depicted above were extended to multivariate models that included the full set of five predictors. These models were of the form:

$$
\log \left(Y_{i}\right)=B_{0}{ }^{k}+\Sigma B_{j}^{k} X_{i j}+U_{i}
$$

where $\Sigma B_{j}{ }^{k} X_{i j}$ represented the joint effects of each of the five predictors, with the sample stratified by MAOA. Tests of the equality of the slope parameters across MAOA activity levels served as the test of the $\mathrm{G} \times \mathrm{E}$ interaction for each individual risk factor. An overall test of the total $\mathrm{G} \times \mathrm{E}$ interaction for each outcome was obtained by subtracting the log likelihood $\chi^{2}$ goodness of fit for a non-nested model (with no interactions modelled) from that of the multilevel nested model, for each of the three outcomes.

In addition, to illustrate the strength of the interactions between MAOA and the combined predictor set, a weighted risk factor index score was created using the following procedure. Each of the three outcomes was separately regressed onto the five environmental/personal risk factors simultaneously. The resulting regression parameters were then used as weights to create a risk index score for each participant corresponding to the weighted total exposure to adverse environmental/personal factors for each outcome. The risk index scores for each outcome were then divided into percentile groupings $(1-60 \%$; 61-80\%; $81-95 \%$; 96-100\%) to create a four-level classification of risk for each outcome. This weighted risk index was then used as the predictor 
in a series of three moderated Poisson regression models of the form noted in equation 1 (above), in which self-reported violent offending, property offending, and official convictions were modelled as a function of the weighted risk factor index score, nested within MAOA. The resulting model parameters were used to derive log-linear predictions of the mean rate of each of the three outcomes for each level of the predictor; these scores were then plotted to illustrate the strength of the $G \times E$ interaction in predicting each of the three outcomes. In addition, the observed values for each level of the weighted risk factor index score for each outcome were also plotted. Finally, in order to test the sensitivity of these findings to alternative modelling procedures, all analyses were repeated using additive linear models fitted to the data in place of the Poisson models. In all cases, similar results were obtained.

\section{Results}

\section{Correlations between genotype and environmental/personal factors}

In order to examine possible gene-environment correlations, Pearson product-moment correlations were calculated for MAOA genotype and each of the five environmental/personal risk factors. These correlations ranged from -0.13 to 0.03 , and only one (MAOA and family material deprivation) was statistically significant $(P<0.01)$.

\section{Bivariate tests of $\mathbf{G} \times \mathbf{E}$ interaction}

Table 1 shows the cohort of males stratified into groups of lowand high-activity MAOA genotype. For each of these groups Table 1 reports mean scores on measures of: (a) self-reported property offending (15-30 years); (b) self-reported violent offending (15-30 years); and (c) officially recorded convictions (17-21 years). Table 1 is further stratified by a series of environmental and personal predictors of offending including: maternal smoking during pregnancy; family material deprivation; child IQ; childhood maltreatment exposure; and leaving school without qualifications. Each category in Table 1 reports tests of $\mathrm{G} \times \mathrm{E}$ interactions by testing the equality of the slope between each risk factor and each outcome across the low-activity and high-activity MAOA groups using moderated Poisson regression models (see Method). These analyses suggest the presence of pervasive $\mathrm{G} \times \mathrm{E}$ interactions in which members of the low-activity MAOA group had elevated rates of offending when members of this group were exposed to various risk factors.

1 For self-reported violent offending (15-30 years) there was evidence of $\mathrm{G} \times \mathrm{E}$ interactions involving $M A O A$ and: maternal smoking during pregnancy $(P<0.0001)$; family material deprivation $(P<0.0001)$; child IQ $(P<0.0001)$; childhood maltreatment exposure $(P<0.001)$; and leaving school without qualifications $(P<0.0001)$.

2 For self-reported property offending, there were significant $\mathrm{G} \times \mathrm{E}$ interactions involving $M A O A$ and: maternal smoking $(P<0.0001)$; family material deprivation $(P<0.001)$; child IQ $(P<0.0001)$; childhood maltreatment $(P<0.0001)$; and leaving school without qualifications $(P<0.0001)$.

3 For officially recorded convictions, significant $\mathrm{G} \times \mathrm{E}$ interactions were in evidence for: smoking during pregnancy $(P<0.0001)$; material deprivation $(P<0.001)$; and leaving school without qualifications $(P<0.05)$.

A potential problem with the results in Table 1 is that it reports multiple tests of $\mathrm{G} \times \mathrm{E}$ interaction, thereby increasing risks of Type I error due to multiple tests. One approach to addressing the problems of multiple tests is to apply a Bonferroni corrected significance level, which for these comparisons was adjusted to 0.003 . Of the 13 significant $\mathrm{G} \times \mathrm{E}$ interactions shown in Table 1 , 12 were significant using the Bonferroni corrected $P$ and 1 nonsignificant (for convictions age 17-21, the predictor 'leaving

Table 1 Mean self-reported violent and property offending (ages 15-30) and officially recorded convictions (ages 17-21) by risk factor and level of MAOA activity, and tests of $\mathrm{G} \times \mathrm{E}$ interaction

\begin{tabular}{|c|c|c|c|c|c|c|}
\hline \multirow[b]{2}{*}{ Risk factor } & \multicolumn{2}{|c|}{$\begin{array}{l}\text { Mean self-reported violent } \\
\text { offending, ages } 15-30\end{array}$} & \multicolumn{2}{|c|}{$\begin{array}{l}\text { Mean self-reported property } \\
\text { offending, ages } 15-30\end{array}$} & \multicolumn{2}{|c|}{$\begin{array}{l}\text { Mean convictions for violent/ } \\
\text { property offending, ages } 17-21\end{array}$} \\
\hline & $\begin{array}{l}\text { LOW MAOA } \\
\qquad(n=150)\end{array}$ & $\begin{array}{l}\text { High MAOA } \\
\quad(n=249)\end{array}$ & $\begin{array}{l}\text { Low MAOA } \\
(n=150)\end{array}$ & $\begin{array}{l}\text { High MAOA } \\
\qquad(n=249)\end{array}$ & $\begin{array}{l}\text { Low MAOA } \\
(n=143)\end{array}$ & $\begin{array}{l}\text { High MAOA } \\
\qquad(n=236)\end{array}$ \\
\hline \multicolumn{7}{|l|}{ Maternal smoking during pregnancy } \\
\hline Yes & 46.9 & 6.3 & 72.3 & 7.0 & 1.2 & 0.4 \\
\hline No & 4.1 & 6.5 & 3.7 & 6.9 & 0.1 & 0.3 \\
\hline Test of equality of slope parameters ( $\chi^{2} 1$ d.f.) & \multicolumn{2}{|c|}{$26.1, P<0.0001$} & \multicolumn{2}{|c|}{$30.6, P<0.0001$} & \multicolumn{2}{|c|}{ 40.0, $P<0.0001$} \\
\hline \multicolumn{7}{|l|}{ Family material deprivation } \\
\hline High & 47.2 & 5.8 & 66.7 & 8.3 & 1.2 & 0.3 \\
\hline Medium & 10.1 & 6.7 & 13.9 & 6.2 & 0.3 & 0.4 \\
\hline Low & 1.2 & 4.0 & 5.0 & 5.7 & 0.1 & 0.1 \\
\hline Test of equality of slope parameters ( $\chi^{2} 1$ d.f.) & \multicolumn{2}{|c|}{$16.9, P<0.0001$} & \multicolumn{2}{|c|}{$11.7, P<0.001$} & \multicolumn{2}{|c|}{$11.4 P<0.001$} \\
\hline \multicolumn{7}{|l|}{ Childhood IQ } \\
\hline Lowest quartile & 58.8 & 8.7 & 85.4 & 9.3 & 1.3 & 1.1 \\
\hline $26-50 \%$ & 3.6 & 12.6 & 5.5 & 7.7 & 0.3 & 0.4 \\
\hline $51-75 \%$ & 1.7 & 3.5 & 3.4 & 4.6 & 0.0 & 0.1 \\
\hline Highest quartile & 3.9 & 3.4 & 5.1 & 6.6 & 0.0 & 0.1 \\
\hline Test of equality of slope parameters ( $\chi^{2} 1$ d.f.) & \multicolumn{2}{|c|}{ 17.3, $P<0.0001$} & \multicolumn{2}{|c|}{$26.2, P<0.0001$} & \multicolumn{2}{|c|}{$1.5, P>0.20$} \\
\hline \multicolumn{7}{|l|}{ Childhood maltreatment exposure } \\
\hline Yes & 68.5 & 11.8 & 116.0 & 10.5 & 1.1 & 0.6 \\
\hline No & 6.4 & 4.9 & 5.0 & 5.8 & 0.4 & 0.3 \\
\hline Test of equality of slope parameters ( $\chi^{2} 1$ d.f.) & \multicolumn{2}{|c|}{$11.9, P<0.001$} & \multicolumn{2}{|c|}{ 29.3, $P<0.0001$} & \multicolumn{2}{|c|}{$0.6, P>0.40$} \\
\hline \multicolumn{7}{|l|}{ Leaving school without qualifications } \\
\hline Yes & 65.8 & 12.8 & 94.2 & 8.7 & 1.7 & 1.1 \\
\hline No & 3.9 & 5.3 & 6.3 & 6.5 & 0.1 & 0.2 \\
\hline Test of equality of slope parameters ( $\chi^{2} 1$ d.f.) & \multicolumn{2}{|c|}{$17.9, P<0.0001$} & \multicolumn{2}{|c|}{$22.4, P<0.0001$} & \multicolumn{2}{|c|}{$5.1, P<0.05$} \\
\hline
\end{tabular}


school without qualifications'). The results of the Bonferronicorrected analyses suggest that it is unlikely that the pervasive $\mathrm{G} \times \mathrm{E}$ interactions in Table 1 can be attributed to Type 1 statistical errors arising from the application of multiple tests of significance.

\section{Multivariate models}

In the next step of the analyses, the risk factors shown in Table 1 were entered into a series of three multivariate nested Poisson regression models in which the five risk factor variables were used to predict each outcome (property offending ages 15-30; violent offending ages 15-30; convictions ages 17-21) when the sample was stratified by MAOA. Each model led to multivariate tests of $\mathrm{G} \times \mathrm{E}$ interaction between $M A O A$ and each environmental or personal risk factor variable (see Method). The results of this analysis are presented in Table 2, which shows estimates of the model parameters for the low-activity and high-activity MAOA groups for each of the outcome measures. Table 2 also shows the individual tests of equality of slope parameters $(\mathrm{G} \times \mathrm{E}$ interactions), and reports on the overall test of $G \times E$ interaction for each outcome. The findings in Table 2 lead to the following conclusions.

\section{Violent offending:}

There were three significant $\mathrm{G} \times \mathrm{E}$ interactions for the measure of violent offending: family material deprivation $(P<0.05)$; childhood IQ $(P<0.001)$; and childhood maltreatment $(P<0.05)$. The overall $\log$ likelihood ratio $\chi^{2}$-test showed the presence of a highly significant $\mathrm{G} \times \mathrm{E}$ interaction between the risk factor variables in Table 2 and $M A O A$ for the measure of violent offending ages 15-30 $(P<0.0001)$.

\section{Property offending}

There were four significant $G \times E$ interactions for the measure of property offending: maternal smoking during pregnancy $(P<0.05)$; childhood IQ $(P<0.01)$; exposure to childhood maltreatment $(P<0.0001)$; and leaving school without qualifications $(P<0.01)$. The overall $\log$ likelihood ratio $\chi^{2}$-test of the $\mathrm{G} \times \mathrm{E}$ interaction again was highly significant $(P<0.0001)$.

Convictions

There were two significant $G \times E$ interactions for the measure of convictions, including: maternal smoking during pregnancy and leaving school without qualifications $(P<0.01)$. The overall $\log$ likelihood ratio $\chi^{2}$-test of $\mathrm{G} \times \mathrm{E}$ interaction was again highly significant $(P<0.0001)$.

\section{Plots of $\mathbf{G} \times \mathbf{E}$ interactions}

To illustrate the strength of the $\mathrm{G} \times \mathrm{E}$ interactions in predicting self-reported violent offending, property offending and official convictions, three further analyses were conducted. In these analyses, the rate of each outcome (violent offending, property offending, convictions) was predicted using a weighted risk factor index derived from the five adverse environmental/personal risk factors that cohort members were exposed to, with the effect of the risk factor count measure nested within low- and high-activity MAOA genotypes (see Method). These values are plotted in Figs $1-3$, which show the predicted values at each level of the risk factor predictor for rates of violent offending (Fig. 1), property offending (Fig. 2) and convictions (Fig. 3). The observed values for each level of the weighted risk factor index for each outcome were also plotted. In all cases, the plots show clear increases in risks of violent crime, property crime and convictions with increasing exposure to risk factors among the low-activity MAOA

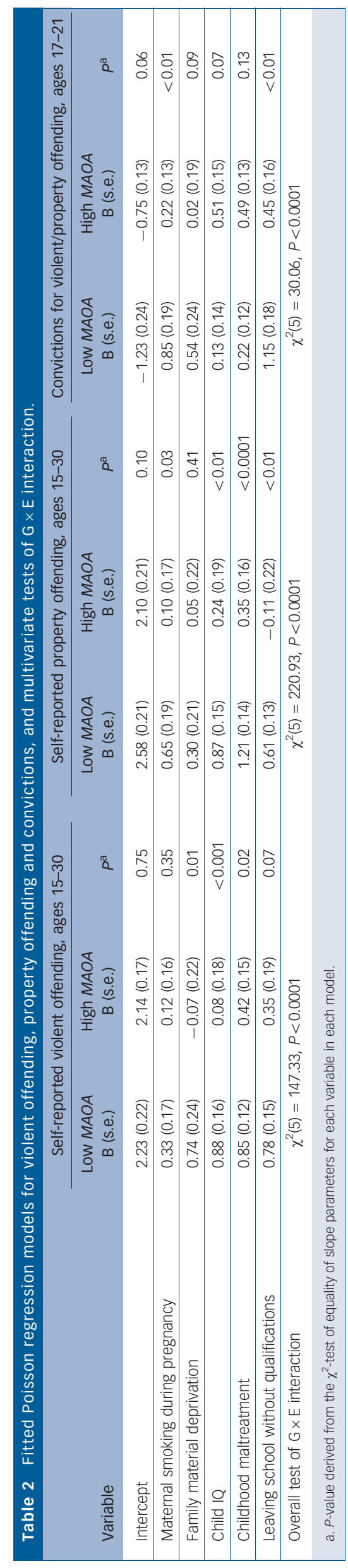




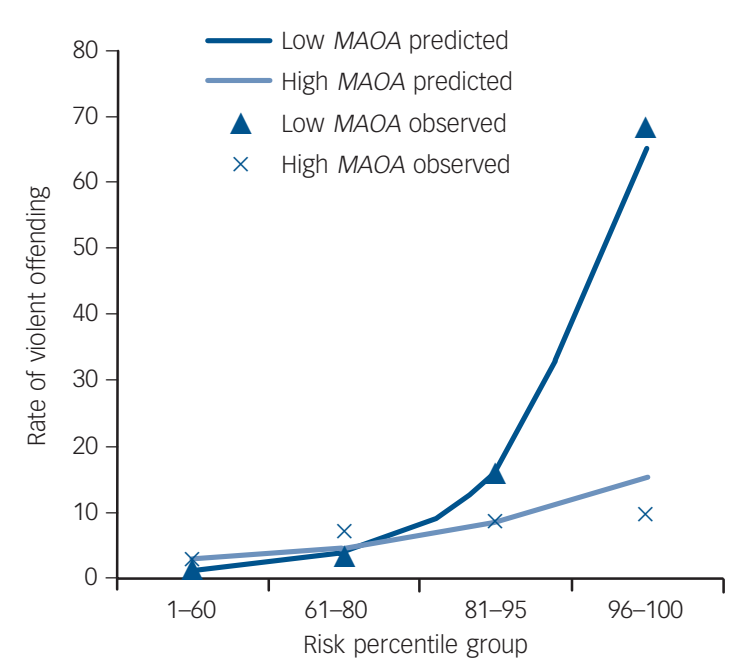

Fig. 1 Observed and predicted rates of violent offending by severity of childhood risk factor index, for each level of MAOA genotype.

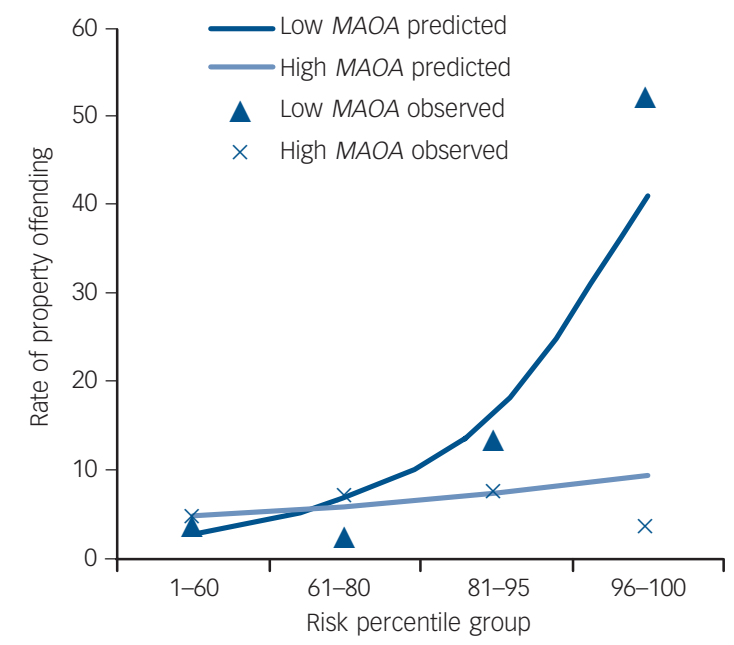

Fig. 2 Observed and predicted rates of property offending by severity of childhood risk factor index, for each level of MAOA genotype.

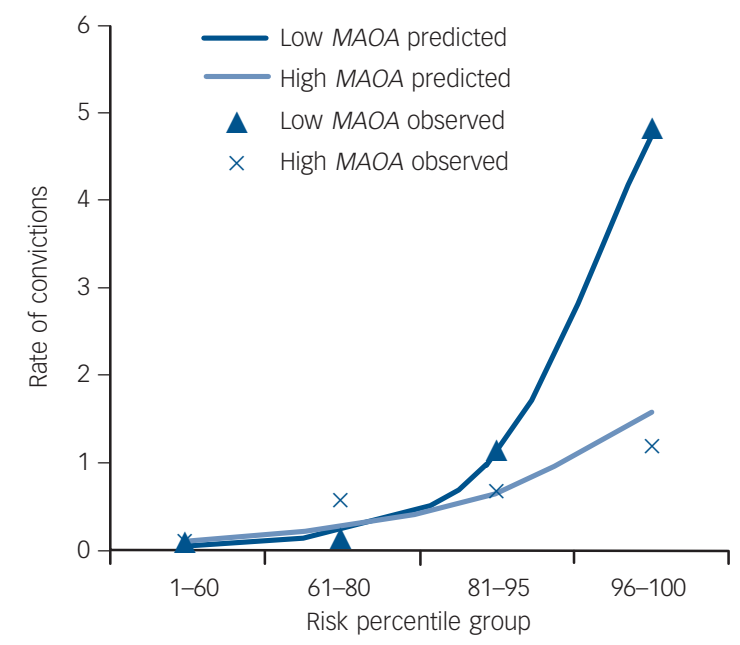

Fig. 3 Observed and predicted rates of convictions by severity of childhood risk factor index, for each level of MAOA genotype. group. In contrast, the rates of increase in risks of crime for the high-activity MAOA group were modest.

\section{Supplementary analyses - ethnic stratification}

To account for ethnic variations in the sample, the analyses were replicated omitting participants of Maori, Pacific Island and Asian ethnicity $(n=47)$. The results of these analyses were similar to those reported above.

\section{Discussion}

The present study used data gathered over the course of a 30-year longitudinal study to examine $\mathrm{G} \times \mathrm{E}$ interactions involving $M A O A$ and multiple risk factors in the development of criminal behaviours. This research was aimed at exploring the conjecture that the genotype for MAOA activity level interacts with multiple risk factors for crime, such that those with the low-activity variant of MAOA will show greater increases in rates of crime when exposed to adverse conditions than the corresponding group having the high-activity variant of MAOA. The analyses in this paper provided strong support for this conjecture.

In particular, analyses of specific risk factors showed the presence of pervasive $\mathrm{G} \times \mathrm{E}$ interactions involving $M A O A$ and: maternal smoking during pregnancy; family material deprivation; childhood IQ; childhood maltreatment; and leaving school without qualifications. Although the results varied between outcomes, the overall findings suggest a clear tendency for those with the low-activity variant of MAOA to be more susceptible to forms of environmental and personal adversity. Multivariate analyses showed highly significant $\mathrm{G} \times \mathrm{E}$ interactions involving $M A O A$ and the risk factor variables. The illustrative plots in Figs 1-3 suggest that the MAOA genotype substantially modified the slope of the relationship between a combined measure of exposure to risk factors and rates of criminal behaviour.

Collectively, these findings provide strong support for the conclusion that, for this cohort, the MAOA activity level genotype appeared to interact with multiple risk factors involved in the development of crime. These factors spanned: maternal smoking during pregnancy; family material deprivation; child IQ; childhood maltreatment; and school failure. In all cases the findings suggest that carriers of the low-activity MAOA genotype showed greater increases in rates of criminal behaviour when exposed to adversity than the corresponding group with the high-activity variant. The findings are congruent with those of a range of studies that have found evidence of increased antisocial behaviour among individuals with the low-activity variant of the MAOA genotype, who have also been exposed to adverse environmental conditions. ${ }^{2-13,19}$ In particular, the study provides further replication and extension of the findings by Caspi et al. ${ }^{1}$ However, the present study suggests that the environmental effects critical to the link between MAOA genotype and antisocial behaviour are not limited to abuse exposure and maternal smoking, but in fact may span a wider range of disadvantageous personal and environmental factors, including material deprivation, lower cognitive ability and poor school achievement.

\section{Implications}

These findings, if replicated, have important implications for the development of theory and research into $\mathrm{G} \times \mathrm{E}$ interaction. In particular, it has been noted that the original findings of $\mathrm{G} \times \mathrm{E}$ interaction evoked considerable enthusiasm as it provided an exemplar of the ways in which genes and environment may interact in the development of complex phenotypical behaviours such as crime. However, following this initial enthusiasm, 
considerable doubts have been expressed about the stability and replicability of $\mathrm{G} \times \mathrm{E}$ findings, with a number of analyses pointing to difficulties with replicating $\mathrm{G} \times \mathrm{E}$ interactions involving single genes and single environmental exposures. ${ }^{35,36}$ These difficulties in replication are to be expected in studies of single genes and specific environmental factors because of the small effect sizes involved and the statistical difficulties and demands of replicating small interactive relationships. The implication of these comments is that if $\mathrm{G} \times \mathrm{E}$ research is to yield stable replicable findings it is important that the $\mathrm{G} \times \mathrm{E}$ interaction is large. There are two ways of increasing the size of potential $\mathrm{G} \times \mathrm{E}$ interactions. The first is to develop models using multiple genes to assess individual genetic vulnerability and estimate $G \times E$ interaction using measures of genetic vulnerability rather than using single genes. The alternative strategy is to develop models of the ways in which a single gene may interact with multiple environmental adversities, as we have demonstrated in the present study. In this approach the use of multiple $\mathrm{G} \times \mathrm{E}$ interactions will increase the overall explanatory contribution of these interactions, making the replication of findings more likely.

\section{Limitations}

One limitation of the present study is that the interactions between MAOA activity genotype and risk factors in predicting criminal behaviour outcomes have been observed only in a sample of males. Several studies have either failed to find evidence of $M A O A$ interactions among females, or have found reversals of the interaction in female samples, such that females with the high-activity variant of $M A O A$ and exposure to adversity were more likely to engage in antisocial behaviour. ${ }^{8,9,19,37,38}$ Further studies are needed to clarify the nature of possible gender differences in the interaction between MAOA genotype and exposure to various forms of environmental and personal adversity. A further issue is that it may be possible that other genes besides MAOA are involved in the development of the environmental/personal factors in the present study, and in the development of criminal behaviour. Further research is needed to better understand the wider genetic bases of these environmental exposures and behaviours. Another limitation of the present study is that it could be argued that some of the environmental exposures used in these analyses were to some extent causally contingent upon other environmental exposures, rather than being independently causal in nature. Structural equation modelling of the interrelationships between these exposures in predicting antisocial behaviour outcomes may be useful in elucidating these issues. In addition, it should be noted that it was only possible to examine possible ethnic stratification of the sample via selfreported ethnicity, rather than a full genomic control analysis, ${ }^{39}$ for which the required information was not available.

\section{Funding}

This research was funded by grants from the Health Research Council of New Zealand, the National Child Health Research Foundation, the Canterbury Medical Research Foundation, the New Zealand Lottery Grants Board, the University of Otago, the Carney Centre for Pharmacogenomics, the James Hume Bequest Fund, and US NIH grant MHO77874.

David M. Fergusson, PhD, Joseph M. Boden, PhD, L. John Horwood, MSC, Christchurch Health \& Development Study, Department of Psychological Medicine, University of Otago, Christchurch; Allison Miller, BSc, DipSc, Martin A. Kennedy $\mathrm{PhD}$, Gene Structure and Function Laboratory, Department of Pathology, University of Otago, Christchurch, New Zealand

Correspondence: Professor David Fergusson, Christchurch Health and Development Study, University of Otago, Christchurch, PO Box 4345, Christchurch, New Zealand. Email: dm.fergusson@otago.ac.nz

First received 16 Feb 2011, final revision 18 Sep 2011, accepted 26 Oct 2011

\section{References}

1 Caspi A, McClay J, Moffitt TE, Mill J, Martin J, Craig IW, et al. Role of genotype in the cycle of violence in maltreated children. Science 2002; 297: 851-4.

2 Beach SR, Brody GH, Gunter TD, Packer H, Wernett P, Philibert RA. Child maltreatment moderates the association of MAOA with symptoms of depression and antisocial personality disorder. J Fam Psychol 2010; 24: 12-20.

3 Weder N, Yang BZ, Douglas-Palumberi H, Massey J, Krystal JH, Gelernter J, et al. MAOA genotype, maltreatment, and aggressive behavior: the changing impact of genotype at varying levels of trauma. Biol Psychiatry 2009; 65: 417-24.

4 Frazzetto G, Di Lorenzo G, Carola V, Proietti L, Sokolowska E, Siracusano A, et al. Early trauma and increased risk for physical aggression during adulthood: the moderating role of MAOA genotype. PLOS One 2007; 2: e486.

5 Reif A, Rosler M, Freitag CM, Schneider M, Eujen A, Kissling C, et al. Nature and nurture predispose to violent behavior: serotonergic genes and adverse childhood environment. Neuropsychopharmacology 2007; 32: 2375-83.

6 Widom CS, Brzustowicz LM. MAOA and the 'cycle of violence': childhood abuse and neglect, MAOA genotype, and risk for violent and antisocial behavior. Biol Psychiatry 2006; 60: 684-9.

7 Kim-Cohen J, Caspi A, Taylor A, Williams B, Newcombe R, Craig IW, et al. $M A O A$, maltreatment, and gene-environment interaction predicting children's mental health: new evidence and a meta-analysis. Mol Psychiatry 2006; 11: 903-13.

8 Huang YY, Cate SP, Battistuzzi C, Oquendo MA, Brent D, Mann JJ. An association between a functional polymorphism in the monoamine oxidase a gene promoter, impulsive traits and early abuse experiences. Neuropsychopharmacology 2004; 29: 1498-505.

9 Aslund C, Nordquist N, Comasco E, Leppert J, Oreland L, Nilsson KW. Maltreatment, MAOA, and delinquency: sex differences in gene-environment interaction in a large population-based cohort of adolescents. Behav Genet 2010; 41: 262-72.

10 Derringer J, Krueger RF, Irons DE, Iacono WG. Harsh discipline, childhood sexual assault, and MAOA genotype: an investigation of main and interactive effects on diverse clinical externalizing outcomes. Behav Genet 2010; 40: 639-48.

11 Ducci F, Enoch MA, Hodgkinson C, Xu K, Catena M, Robin RW, et al. Interaction between a functional MAOA locus and childhood sexual abuse predicts alcoholism and antisocial personality disorder in adult women. Mol Psychiatry 2008; 13: 334-47.

12 Enoch MA, Steer CD, Newman TK, Gibson N, Goldman D. Early life stress, $M A O A$, and gene-environment interactions predict behavioral disinhibition in children. Genes Brain Behav 2010; 9: 65-74

13 Nilsson KW, Sjoberg RL, Damberg M, Leppert J, Ohrvik J, Alm PO, et al. Role of monoamine oxidase A genotype and psychosocial factors in male adolescent criminal activity. Biol Psychiatry 2006; 59: 121-7.

14 Huizinga D, Haberstick BC, Smolen A, Menard S, Young SE, Corley RP, et al. Childhood maltreatment, subsequent antisocial behavior, and the role of monoamine oxidase A genotype. Biol Psychiatry 2006; 60: 677-83.

15 Haberstick BC, Lessem JM, Hopfer CJ, Smolen A, Ehringer MA, Timberlake D, et al. Monoamine oxidase $A(M A O A)$ and antisocial behaviors in the presence of childhood and adolescent maltreatment. Am J Med Genet $B$ Neuropsychiatr Genet 2005; 135B: 59-64.

16 Prichard Z, Mackinnon A, Jorm AF, Easteal S. No evidence for interaction between MAOA and childhood adversity for antisocial behavior. Am J Med Genet B Neuropsychiatr Genet 2008; 147B: 228-32.

17 Prom-Wormley EC, Eaves LJ, Foley DL, Gardner CO, Archer KJ, Wormley BK, et al. Monoamine oxidase $A$ and childhood adversity as risk factors for conduct disorder in females. Psychol Med 2009; 39: 579-90.

18 van der Vegt EJ, Oostra BA, Arias-Vasquez A, van der Ende J, Verhulst FC, Tiemeier $\mathrm{H}$. High activity of monoamine oxidase A is associated with externalizing behaviour in maltreated and nonmaltreated adoptees. Psychiatr Genet 2009; 19: 209-11.

19 Wakschlag LS, Kistner EO, Pine DS, Biesecker G, Pickett KE, Skol AD, et al. Interaction of prenatal exposure to cigarettes and MAOA genotype in pathways to youth antisocial behavior. Mol Psychiatry 2010; 15: 928-37.

20 Fergusson DM, Horwood $L$. The Christchurch Health and Development Study: review of findings on child and adolescent mental health. Aust N Z J Psychiatry 2001; 35: 287-96.

21 Fergusson DM, Horwood U, Shannon FT, Lawton JM. The Christchurch Child Development Study: a review of epidemiological findings. Paediatr Perinat Epidemiol 1989; 3: 278-301.

22 Sabol SZ, Hu S, Hamer D. A functional polymorphism in the monoamine oxidase A gene promoter. Hum Genet 1998; 103: 273-9. 
23 Moffitt TR, Silva PA. Self-reported delinquency: results from an instrument for New Zealand. Aust NZ J Crim 1988; 21: 227-40.

24 Elliott DS, Huizinga D. Improving self-reported measures of delinquency. In Cross-national Research in Self-reported Crime and Delinquency (ed MW Klein): 155-86. Kluwer, 1989.

25 Fergusson DM, Horwood LJ. Alcohol abuse and crime: a fixed effects regression analysis. Addiction 2000; 95: 1525-36.

26 Fergusson DM, Swain-Campbell N, Horwood LJ. How does childhood economic disadvantage lead to crime? J Child Psychol Psychiatry 2004; 45: 956-66.

27 Fergusson DM, Horwood LJ, Nagin DS. Offending trajectories in a New Zealand birth cohort. Criminology 2000; 38: 525-51.

28 Fergusson DM, Boden JM, Horwood L, Miller AL, Kennedy MA. MAOA, abuse exposure and antisocial behaviour: 30-year longitudinal study. Br J Psychiatry 2011; 198: 457-63.

29 Wechsler D. Manual for the Wechsler Intelligence Scale for Children Revised. Psychological Corporation, 1974.

30 Fergusson DM, Horwood LJ, Woodward LJ. The stability of child abuse reports: a longitudinal study of young adults. Psychol Med 2000; 30: 529-44.

31 Fergusson DM, Lynskey MT, Horwood $\amalg$. Childhood sexual abuse and psychiatric disorder in young adulthood: I. Prevalence of sexual abuse and factors associated with sexual abuse. J Am Acad Child Adolesc Psychiatry 1996; 35: 1355-64.
32 Fergusson DM, Lynskey MT. Physical punishment/maltreatment during childhood and adjustment in young adulthood. Child Abuse Negl 1997; 21 617-30.

33 Fergusson DM, Horwood $\mathrm{L}$, Boden JM. Structural equation modeling of repeated retrospective reports of childhood maltreatment. Int $J$ Methods Psychiatr Res 2011; 20: 93-104.

34 Hox JJ. Multilevel Analysis: Techniques and Applications (2nd edn): 66-8. Routledge, 2010

35 Munafò $M$, Flint J. Replication and heterogeneity in gene $x$ environment interaction studies. Int J Neuropsychopharmacol 2009; 12: 727-9.

36 Monroe SM, Reid MW. Gene-environment interactions in depression research: genetic polymorphisms and life-stress polyprocedures. Psychol Sci 2008; 19: 947-56.

37 Vanyukov MM, Maher BS, Devlin B, Kirillova GP, Kirisci L, Yu LM, et al. The MAOA promoter polymorphism, disruptive behavior disorders, and early onset substance use disorder: gene-environment interaction. Psychiatr Genet 2007; 17: 323-32.

38 Sjoberg RL, Nilsson KW, Wargelius $\mathrm{HL}$, Leppert J, Lindstrom L, Oreland L. Adolescent girls and criminal activity: role of MAOA-LPR genotype and psychosocial factors. Am J Med Genet B Neuropsychiatr Genet 2007; 144B: 159-64.

39 Voorman A, Lumley T, McKnight B, Rice K. Behavior of QQ-plots and genomic control in studies of gene-environment interaction. PLOS One 2011; 6: e19416. 